\title{
Downregulation of calbindin 1, a calcium-binding protein, reduces the proliferation of osteosarcoma cells
}

\author{
ZHENGXIANG HUANG $^{1 *}$, GUOJUN FAN $^{2 *}$ and DONGLIANG WANG ${ }^{1}$ \\ ${ }^{1}$ Department of Orthopedic Surgery, Xinhua Hospital, Shanghai Jiaotong University School of Medicine, Shanghai 200092; \\ ${ }^{2}$ Department of Orthopedic Surgery, The First People's Hospital of Urumqi, Urumqi, Xinjiang 830000, P.R. China
}

Received August 27, 2015; Accepted January 13, 2017

DOI: $10.3892 / 01.2017 .5931$

\begin{abstract}
Osteosarcoma is the most common type of primary malignant bone tumor and has a high propensity to metastasize to the lungs and bones. Calbindin $1(C A L B 1)$ is a constituent $\mathrm{Ca}^{2+}$ binding protein, which can prevent apoptotic death in several cell types induced through various pro-apoptotic signaling pathways. To investigate whether $C A L B 1$ is implicated in the tumor growth of human osteosarcoma, two different short hairpin RNAs (shRNAs) against $C A L B 1$ were used for $C A L B 1$-knockdown in osteosarcoma U2OS cells. The U2OS cells were divided into three groups: Two groups with CALB1 knockdown (CALB1-shRNA 1 and CALB1-shRNA 2) and one control group (Con-shRNA). Reverse transcription-quantitative polymerase chain reaction and western blot analysis confirmed that the CALB1-shRNA 1- and 2-infected cells exhibited significantly lower levels of $C A L B 1$ gene and protein expression compared with the Con-shRNA group. The proliferation and colony formation abilities were significantly inhibited in CALB1-deficient U2OS cells compared with the control, as measured using an MTT assay and crystal violet staining. Flow cytometry revealed that the number of CALB1-shRNA 2-injected cells was increased in the $\mathrm{G}_{0} / \mathrm{G}_{1}$ and $\mathrm{G}_{2} / \mathrm{M}$ phases, but decreased in the $\mathrm{S}$ phase, compared with the control group. The assessment of apoptosis and necrosis using Annexin V/7-aminoactinomycin D demonstrated that there was a significantly higher percentage of necrotic, early apoptotic, and late apoptotic cells, but a significantly lower percentage of viable cells in U2OS cells with $C A L B 1$-knockdown compared with the control group. In conclusion, $C A L B 1$ contributes to protecting osteosarcoma cells from apoptosis and provides a
\end{abstract}

Correspondence to: Dr Dongliang Wang, Department of Orthopedic Surgery, Xinhua Hospital, Shanghai Jiaotong University School of Medicine, 1665 Kongjiang Road, Yangpu, Shanghai 200092, P.R. China

E-mail: dongliangwangdr@163.com

${ }^{*}$ Contributed equally

Key words: osteosarcoma, calbindin 1, knockdown, proliferation, apoptosis potential novel target for gene therapy to treat patients with osteosarcoma.

\section{Introduction}

Osteosarcoma originates from primitive bone-forming mesenchymal cells and has been identified as an aggressive sarcoma of the bone $(1,2)$. The incidence rate of osteosarcoma is $0.42 \%$ in inhabitants in USA, and osteosarcoma occurs most frequently in adolescents and young adults $(3,4)$. Furthermore, distant metastases are common in patients with osteosarcoma, with primary migration to the lungs and bones, and a poor prognosis following recurrence and metastasis $(5,6)$.

Current treatment strategies for osteosarcoma include a presurgical window of carboplatin, macroscopic surgical resection, multi-drug chemotherapy and radiotherapy $(7,8)$. Despite advances in the treatment of osteosarcoma, treatment efficacy and short-term survival rates have not improved in recent years $(9,10)$. Thus, the development of a novel therapeutic strategy for cancer treatment is warranted.

Notably, gene therapy holds great promise for providing an innovative cancer treatment (11). Previous studies have identified several candidate gene targets for osteosarcoma gene therapy (12-14). For example, the proliferation inhibition of osteosarcoma U2OS cells has been associated with the repression of $\mathrm{G}_{1} / \mathrm{S}$ cell cycle transition mediated by the overexpression of connexin43 (12). Knockdown of S100 calcium binding protein $\mathrm{A} 4$ is correlated with the reduced proliferation and invasiveness of osteosarcoma MG-63 cells (13). Following the loss of MACC1 MET transcriptional regulator, osteosarcoma cells were demonstrated to be less proliferative and more apoptotic, and exhibited lower colony-forming and invasive abilities (14). However, there are only a few potential therapeutic targets for osteosarcoma, thus the identification of novel candidate genes is warranted to provide more viable clinical therapeutic strategies for the treatment of the disease.

Calbindin 1 (CALB1) is a member of the EF-hand helix-loop-helix intracellular $\mathrm{Ca}^{2+}$-binding protein family and is mapped to human chromosome $8 \mathrm{q} 21.3-\mathrm{q} 22.1(15,16)$. CALB1 is expressed normally in osteoblast cells and is involved in the formation of mineralized bone matrix (17). Margolis et al (18) demonstrated that $C A L B 1$ serves an essential role in bone remodeling, and that increased bone volume was identified in $C A L B 1$-knockout mice. It has been demonstrated that $C A L B 1$ 
is associated with an anti-apoptotic function in several cell types, including bone cells $(19,20)$. For example, CALBI inhibits apoptosis through preventing caspase-3 activity in osteoblastic cells (21). A previous study also reported that, in osteocytes and osteoblasts, CALB1 serves a protective role against glucocorticoid-induced apoptosis (20). Furthermore, osteocytes are described as terminally-differentiated osteoblasts, which are referred to as osteosarcoma progenitors (22). However, no clear association has been identified between $C A L B 1$ and osteosarcoma.

In the present study, the function of $C A L B 1$ in osteosarcoma growth and progression was investigated. A lentiviral-based system was used to functionally inhibit the expression of $C A L B 1$ in osteosarcoma cells. The cell viability of osteosarcoma cells was measured using MTT, crystal violet staining and flow cytometry assays. This investigation may provide clinicians a viable therapy for osteosarcoma in the future.

\section{Materials and methods}

Cell lines. The U2OS osteosarcoma and 293T human embryonic kidney cell lines were supplied by The Cell Bank of Type Culture Collection of Chinese Academy of Sciences (Shanghai, China). The cells were cultured in Dulbecco's modified Eagle's medium (Hyclone; GE Healthcare Life Sciences, Logan, UT, USA) supplemented with $10 \%$ fetal bovine serum (Biological Industries, Cromwell, CT, USA). The cells were incubated at $37^{\circ} \mathrm{C}$ in a humidified atmosphere consisting of $5 \% \mathrm{CO}_{2}$.

Construction of CALB1 shRNA expression vector. The short hairpin RNA (shRNA) sequences targeting CALB1 were as follows: S1, 5'-CGAACGGATCTTGCTCTTATTCTCGAG AATAAGAGCAAGATCCGTTCGTTTTT-3'; and S2, 5'-GAT TGGAGTTATCACCTGAAACTCGAGTTTCAGGTGATA

ACTCCAATCTTTTT-3', which were designed based on the human $C A L B 1$ gene (National Center for Biotechnology Information accession no., 004929.2). The sequence used as a negative control was as follows: 5'-GCGGAGGG TTTGAAAGAATATCTCGAGATATTCTTTCAAACCCTC CGCTTTTTT-3'. The three oligonucleotides were inserted into pGP vectors (Shanghai Hollybio, Shanghai, China) expressing green fluorescent protein (GFP) at the EcoRI and BamHI cleavage sites.

Packaging and infection for shRNA-expressing lentivirus vectors. To package lentivirus vectors, the reconstructed vectors pGP-CALB1-shRNA 1, pGP-CALB1-shRNA 2 or pGP-Con-shRNA were transfected into $293 \mathrm{~T}$ cells at a confluence of $90 \%$ along with two helper plasmids pVSVG-I and pCMVAR8.92 (Shanghai Hollybio) using Lipofectamine $^{\mathrm{TM}} 2000$ (Invitrogen; Thermo Fisher Scientific, Inc., Waltham, MA, USA). The supernatant was collected at $48 \mathrm{~h}$ post-transfection and the lentiviral particles were harvested through ultracentrifugation at 4,000 $\mathrm{x} g$ for $10 \mathrm{~min}$ at $4^{\circ} \mathrm{C}$, prior to subsequently being passed through a $45-\mu \mathrm{m}$ filter. $\mathrm{U} 2 \mathrm{OS}$ cells were cultured for $72 \mathrm{~h}$ at $37^{\circ} \mathrm{C}$ in 6 -well plates at an inoculation density of $5 \times 10^{4}$ cells/well and infected with the lentivirus containing CALB1-shRNA 1, CALB1-shRNA 2 or Con-shRNA at a multiplicity of infection of 20. The infection efficiency was observed at $72 \mathrm{~h}$ post-infection using fluorescence microscopy.

Quantification of CALB1 $m R N A$ using reverse transcription-quantitative polymerase chain reaction $(R T-q P C R)$. To elucidate the CALB1 mRNA-knockdown efficiency in U2OS cells, total RNA was extracted at 5 days post-infection using Trizol reagent (Invitrogen; Thermo Fisher Scientific, Inc.) and treated with recombinant DNase I (Takara Biotechnology Co., Ltd., Dalian, China). A total of $2 \mu \mathrm{g}$ RNA was then reversed transcribed into cDNA using the SuperScript ${ }^{\mathrm{TM}}$ II Reverse Transcriptase kit (Invitrogen; Thermo Fisher Scientific, Inc.) according to the manufacturer's protocol. The primer sequences used were as follows: CLABl forward, 5'-TGGCATCGGAAGAGCAGCAG-3' and reverse, 5'-TGA CGGAAGTGGTTACCTGGAAG-3'; and $\beta$-actin forward, 5'-GTGGACATCCGCAAAGAC-3' and reverse, 5'-AAAGGG TGTAACGCAACTA-3'. The qPCR $(20 \mu \mathrm{l})$, consisting of $10 \mu 1$ XX SYBR Premix Ex Taq ${ }^{\mathrm{TM}}, 0.8 \mu \mathrm{l}$ forward and reverse primers $(2.5 \mu \mathrm{M}), 5 \mu \mathrm{l}$ cDNA (150 ng), and $4.2 \mu \mathrm{l}$ double distilled (dd) $\mathrm{H}_{2} \mathrm{O}$, was performed using the CFX Connect ${ }^{\mathrm{TM}}$ Real-Time PCR system (BioRad Laboratories, Inc., Hercules, CA, USA) with the following thermocycling conditions: Initial denaturation at $95^{\circ} \mathrm{C}$ for $1 \mathrm{~min}$ and denaturation at $95^{\circ} \mathrm{C}$ for $5 \mathrm{sec}$, followed by $20 \mathrm{sec}$ of annealing and extension at $60^{\circ} \mathrm{C}$ for 40 cycles. The $2^{\Delta \Delta \mathrm{Cq}}$ method was used to calculate the CALB1 mRNA expression between different groups (23). All mRNA expression values were normalized to $\beta$-actin.

Western blot assay for CALB1 protein expression. U2OS cells were washed with ice-cold PBS at 7 days post-infection and solubilized in 2X SDS Sample Buffer [100 mM Tris-HCl (pH 6.8), $10 \mathrm{mM}$ EDTA, 4\% SDS and 10\% glycine]. The precipitated protein was collected through centrifugation at $4^{\circ} \mathrm{C}$ for $10 \mathrm{~min}$ at $12,000 \times \mathrm{g}$. The protein concentrations were then determined using the bicinchoninic BCA protein assay kit (Thermo Fisher Scientific, Inc.). Subsequently, equal amounts of total protein (30 $\mu \mathrm{g} /$ lane) were separated by $10 \%$ SDS-PAGE and transferred onto a polyvinylidene difluoride membrane. The membranes were blocked with $5 \%$ skimmed milk in Tris-buffered saline with Tween-20 [TBST; $150 \mathrm{nmol} / 1 \mathrm{NaCl}$, $100 \mathrm{~m} \mathrm{~mol} / 1$ Tris-base, $0.1 \%$ Tween-20 (pH 7.6)] for $30 \mathrm{~min}$ at room temperature. The membranes were then incubated with rabbit anti-CALB1 (cat. no. 14479-1-AP; 1:500 dilution) or rabbit anti-GAPDH (cat. no. 10494-1-AP; 1:100,000 dilution) primary polyclonal antibodies (both ProteinTech Group, Inc., Chicago, IL, USA) overnight at $4^{\circ} \mathrm{C}$. Following washing with TBST, the blots were incubated with goat anti-rabbit immunoglobulin $\mathrm{G}$ horseradish peroxidase-conjugated secondary antibody (cat. no. sc-2054; 1:5,000 dilution; Santa Cruz Biotechnology, Inc., Dallas, TX, USA) at room temperature for $2 \mathrm{~h}$ and developed with an Amersham ECL Prime Western Blotting Detection Reagent (GE Healthcare Life Sciences, Shanghai, China).

MTT assay. The lentivirus-infected osteosarcoma U2OS cells were seeded into 96-well tissue culture plates at a density of $2 \times 10^{3}$ cells/well and incubated at $37^{\circ} \mathrm{C}$ for between 1 and 5 days. Each day, $20 \mu \mathrm{l}$ MTT solution (Sigma-Aldrich; Merck KGaA, Darmstadt, Germany) was added to each well. Following $4 \mathrm{~h}$ 
of incubation at $37^{\circ} \mathrm{C}$, the medium was discarded and $100 \mu 1$ DMSO was added to each well to dissolve the MTT crystals. Optical density was measured during growth at a wavelength of $595 \mathrm{~nm}$ using a microplate reader.

Colony-forming assay. To evaluate the colony formation capacity of the cells, a low number of $96 \mathrm{~h}$ post-infected osteosarcoma U2OS cells were plated into 6 -well plates at a density of $5 \times 10^{2}$ cells/well. The cells were observed daily, and the medium was changed on the 2nd, 4th, 6th and 8th days. On day 9 , the cells were washed and then fixed with $4 \%$ paraformaldehyde. Subsequently, the cells were washed twice in PBS and stained with freshly prepared crystal violet for $10 \mathrm{~min}$ at room temperature. Following washing with $\mathrm{dd}_{2} \mathrm{O}$, colonies ( $>50$ cells/colony) were counted by eye.

Cell cycle analysis. To monitor cell cycle progression, flow cytometry was performed following staining with propidium iodide (PI). At 3 days post-infection with lentiviral vectors, the U2OS cells were seeded at a density of $7 \times 10^{4}$ cells $/ 6-\mathrm{cm}$ dish and serum starved for $72 \mathrm{~h}$. The cells were harvested by centrifugation at $4^{\circ} \mathrm{C}$ for $5 \mathrm{~min}$ at 2,000 $\mathrm{x} \mathrm{g}$ following digestion with pancreatin, washed 3 times in ice-cold PBS and then fixed in $70 \%$ ethanol, prior to incubation at $4^{\circ} \mathrm{C}$ for $25 \mathrm{~min}$. The ethanol was removed through centrifugation at $4^{\circ} \mathrm{C}$ for $5 \mathrm{~min}$ at 2,000 x $g$ and discarded, and the cell pellet was subsequently resuspended in $10 \mu \mathrm{g} / \mathrm{ml}$ DNAse-free RNase A and incubated for $30 \mathrm{~min}$ at $37^{\circ} \mathrm{C}$. For flow cytometry analysis, $100 \mu \mathrm{l} \mathrm{PI}$ solutions were added to each sample and analyzed using a FACS Calibur II sorter and BD FACSCalibur flow cytometer and CellQuest Pro Software (BD Biosciences, Franklin Lakes, NJ, USA).

Apoptosis detection. Apoptotic cells were quantified according to the protocol of the Annexin V-APC/7-AAD Detection kit (Nanjing KeyGen Biotech Co., Ltd., Nanjing, China). The cells were divided into four groups: i) Unstained cells,

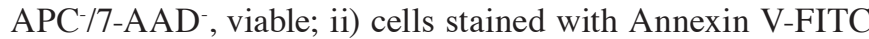
and no 7-AAD, $\mathrm{APC}^{+} / 7-\mathrm{AAD}^{-}$, early apoptotic; iii) cells stained with 7-AAD and no Annexin V-FITC, APC $/ 7-\mathrm{AAD}^{+}$, necrotic; and iv) cells stained with Annexin V-FITC and 7-AAD, $\mathrm{APC}^{+} / 7-\mathrm{AAD}^{+}$, late apoptotic.

Statistical analysis. Statistical analysis was performed using SPSS software package (version 13.0; SPSS, Inc., Chicago, IL, USA). All data are presented as the mean \pm standard deviation following three independent experiments. Student's t-test (unpaired) was conducted for statistical comparisons. $\mathrm{P}<0.05$ was considered to indicate a statistically significant difference.

\section{Results}

Lentiviral-mediated delivery of shCALB1 s results in the knockdown of CALB1 gene and protein expression in osteosarcoma U2OS cells. To identify whether the Con-shRNA and shCALB1 s were successfully infected into U2OS cells, the cellular green fluorescence was observed under a fluorescent microscope. The efficiency of infection was determined by counting the number of cells expressing GFP. The U2OS cells were successfully infected with lentivirus CALB1-shRNA 1,
CALB1-shRNA 2, or Con-shRNA, all exhibiting an infection efficiency of $>80 \%$ (Fig. 1A).

The effect of CALB1-shRNA 1 or 2 lentiviral infection on $C A L B 1$ gene and protein expression levels was then investigated. RT-qPCR results demonstrated that the silencing shRNA-infected groups exhibited significantly lower expression of the CALB1 gene compared with the Con-shRNA group (CALB1-shRNA 1, P<0.01; CALB1-shRNA 2, $\mathrm{P}<0.05$; Fig. 1B). Infection of U2OS cells with CALB1-shRNA 1 or 2 reduced CALB1 protein expression compared with that in cells infected with Con-shRNA (Fig. 1C). These results indicate that lentiviral vectors carrying CALB1-shRNA 1 or 2 can functionally depress $C A L B 1$ gene and protein expression in U2OS cells.

CALB1-knockdown results in the inhibition of proliferative and colony-forming capacity. To detect whether the proliferation of osteosarcoma U2OS cells was affected by $C A L B 1$-knockdown, an MTT viability assay was performed. U2OS cells with the $C A L B 1$-knockdown exhibited decreased cell proliferation from day 3 compared with the control (Fig. 2). Following culturing, significantly reduced proliferation of CALB1-shRNA 1-infected U2OS cells were observed on the 4th $(32.6 \%)$ and 5 th $(36.2 \%)$ days compared with that in the Con-shRNA-infected cells $(\mathrm{P}<0.001$; Fig. 2A). Additionally, the proliferation of the U2OS cells infected with CALB1-shRNA 2 was significantly decreased by the 4th $(30.7 \%)$ and 5 th $(42.0 \%)$ days compared with that in the Con-shRNA-infected group ( $\mathrm{P}<0.001$; Fig. 2B).

Since the proliferative ability of shRNA 1 and shRNA 2 were both markedly impaired in the MTT assay, only one shRNA (shRNA 2) was used in the subsequent experiments. The colony-forming ability of CALB1-shRNA 2 and Con-shRNA cells was measured using the crystal violet staining method. Following 9 days in culture, a decline in the number and size of the colonies was detected in CALB1-shRNA 2-infected U2OS cells compared with the control group (Fig. 2C). The number of colonies was calculated in the CALB1-shRNA 2 and Con-shRNA groups. Fig. 2D illustrates that $C A L B 1$-knockdown resulted in a $94.1 \%$ decrease in colony cell numbers compared with the control group $(\mathrm{P}<0.01)$. These results suggest that $C A L B 1$-knockdown can significantly suppress the proliferative and colony-forming abilities of osteosarcoma U2OS cells.

CALB1-knockdown significantly disrupts the cell cycle progression of U2OS cells. To investigate the potential mechanisms underlying $C A L B 1$-knockdown induced growth inhibition in U2OS cells, the cell cycle progression of Con-shRNA- and CALB1-shRNA 2-infected cells was examined using flow cytometry (Fig. 3A). The results demonstrated that $53.567 \pm 0.137,24.603 \pm 0.420$ and $21.827 \pm 0.508 \%$ of CALB1-shRNA 2 cells were in the $\mathrm{G}_{0} / \mathrm{G}_{1}, \mathrm{~S}$, and $\mathrm{G}_{2} / \mathrm{M}$

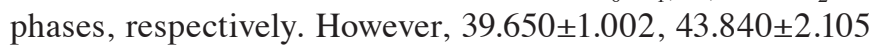
and $16.513 \pm 1.154 \%$ of Con-shRNA cells entered the $G_{0} / G_{1}$, $\mathrm{S}$, and $\mathrm{G}_{2} / \mathrm{M}$ phases. Calculations revealed that, following the knockdown of $C A L B 1$, the proportion of cells was significantly increased in the $\mathrm{G}_{0} / \mathrm{G}_{1}(35.1 \%)$ and $\mathrm{G}_{2} / \mathrm{M}(32.2 \%)$ stages, and significantly decreased in the $\mathrm{S}$ stage $(43.9 \%)$ compared with the control group (all $\mathrm{P}<0.01$ ) (Fig. 3B). These data suggest 


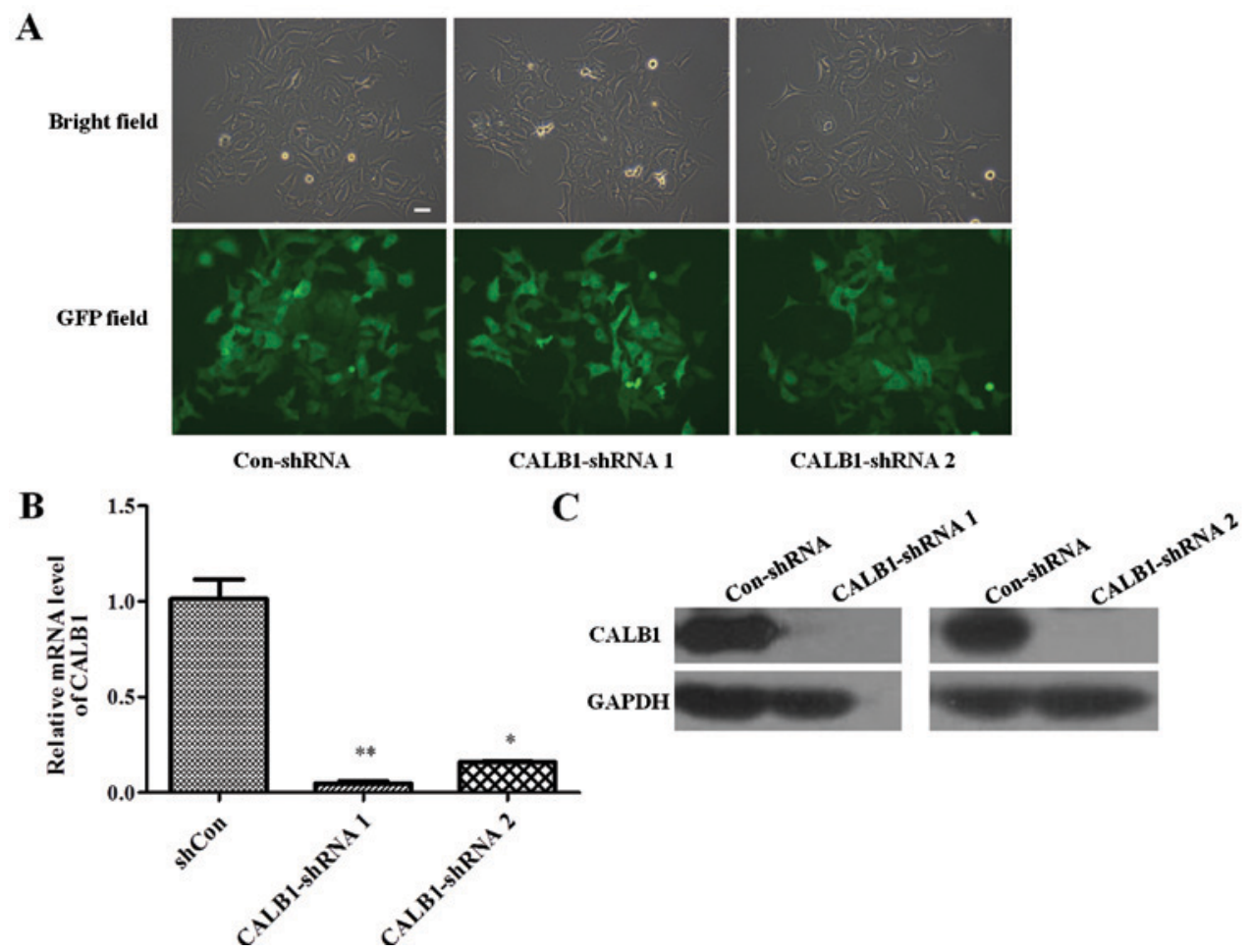

Figure 1. Confirmation of CALB1-knockdown in osteosarcoma U2OS cells with CALB1-shRNA 1 and 2 infection. (A) Expression of GFP in infected U2OS cells was shown in bright-field images and by GFP. Scale bar, $10 \mu \mathrm{m}$. Images were captured at $72 \mathrm{~h}$ post-infection (magnification, $\mathrm{x} 100)$. (B) Quantitative polymerase chain reaction and (C) western blot analysis demonstrating that the CALB1 mRNA and protein levels were knocked down in CALB1-shRNA 1- and 2-infected cells. " $\mathrm{P}<0.05,{ }^{* *} \mathrm{P}<0.01$. CALB1, calbindin 1; GFP, green fluorescent protein; sh, short hairpin; con, negative control.

that the knockdown of $C A L B 1$ induced cell cycle arrest at the $\mathrm{G}_{0} / \mathrm{G}_{1}$ and $\mathrm{G}_{2} / \mathrm{M}$ stages in $\mathrm{U} 2 \mathrm{OS}$ cells.

Induction of necrosis and apoptosis by depletion of CALBI in $U 2 O S$ cells. To understand the mechanisms underlying the suppression of U2OS cell proliferation and colony formation following $C A L B 1$ depletion, cells were probed with Annexin V-FITC/7-AAD and apoptotic cells were quantified using flow cytometry (Fig. 4A). Following infection, $3.07 \pm 0.14 \%$ of Con-shRNA-infected cells entered the early apoptotic stage, while $5.22 \pm 0.18$ and $5.17 \pm 0.35 \%$ of CALB1-shRNA 1 and 2, respectively, entered this stage (Fig. 4B). The percentage of cells that entered the late apoptotic stage were as follows: $20.43 \pm 2.2 \%$, Con-shRNA; $33.90 \pm 0.36 \%$, CALB1-shRNA 1 ; and $30.13 \pm 0.64 \%$, CALB1-shRNA 2 . The percentage of cells that entered the necrotic stage were as follows: $10.98 \pm 0.29 \%$, Con-shRNA; $14.76 \pm 0.14 \%$, CALB1-shRNA 1 ; and $12.00 \pm 0.57 \%$, CALB1-shRNA 2 . A significantly higher percentage of Con-shRNA viable cells $(65.52 \pm 2.12 \%)$ were identified compared with CALB1-shRNA $1(46.13 \pm 0.15 \%$; $\mathrm{P}<0.01)$ and CALB1-shRNA $2(52.69 \pm 0.50 \% ; \mathrm{P}<0.001)$ cells (Fig. 4B). These results indicate that $C A L B 1$-knockdown induces the apoptosis and necrosis of osteosarcoma U2OS cells.

\section{Discussion}

Osteosarcoma is the most common type of malignant bone tumor, with a peak incidence in children and adolescents $(24,25)$. CALB1 is a $28-\mathrm{kDa}$ calcium-binding protein and functions to rescue neuronal, osteocyte, osteoblast and lymphocyte cells from apoptosis $(20,21)$. CALB1 is commonly expressed in classic medulloblastomas, the human medulloblastoma D283 MED cell line and in lung carcinomas $(26,27)$. The present study aimed to investigate the potential role of $C A L B 1$ in osteosarcoma tumor progression. The results revealed that the proliferation and colony formation abilities were inhibited in osteosarcoma U2OS cells following CALB1-knockdown. Notably, accelerated apoptosis of osteosarcoma U2OS cells was observed following the knockdown of CALB1.

Uncontrolled proliferation and escape of cells from apoptotic death are characteristics of cancer cells $(28,29)$. It has been previously demonstrated that anti-growth signals prevent cell proliferation through two different mechanisms: Cells may enter the quiescent state $\left(\mathrm{G}_{0}\right)$ and not participate in the active proliferative cycle; or cells may be induced to enter post-mitotic states and lose the potential to differentiate (28). Fang et al (30) reported that the upregulation of caveolin 1 resulted in $\mathrm{G}_{0} / \mathrm{G}_{1}$ phase arrest in endothelial cells, contributing to the suppression of their proliferation. The results of a previous study demonstrated that the mediator complex subunit 19-knockdown through lentivirus vector shRNA inhibits human osteosarcoma cell proliferation by inducing cell cycle arrest at the $\mathrm{G}_{0} / \mathrm{G}_{1}$ phase (31). Furthermore, a previous study observed decreased proliferation of human esophageal cancer cells following the inhibition of $\beta$-catenin expression (32). In the present study, the absence of CALB1 expression in human osteosarcoma U2OS cells may result in the activation of anti-growth signals, inducing cell cycle arrest at the $\mathrm{G}_{0} / \mathrm{G}_{1}$ phase and disturbance to the $G_{1}$ to $S$ phase transition.

The results of the present study also revealed that the infected $\mathrm{U} 2 \mathrm{OS}$ cells underwent cell cycle arrest at the $\mathrm{G}_{2} / \mathrm{M}$ 

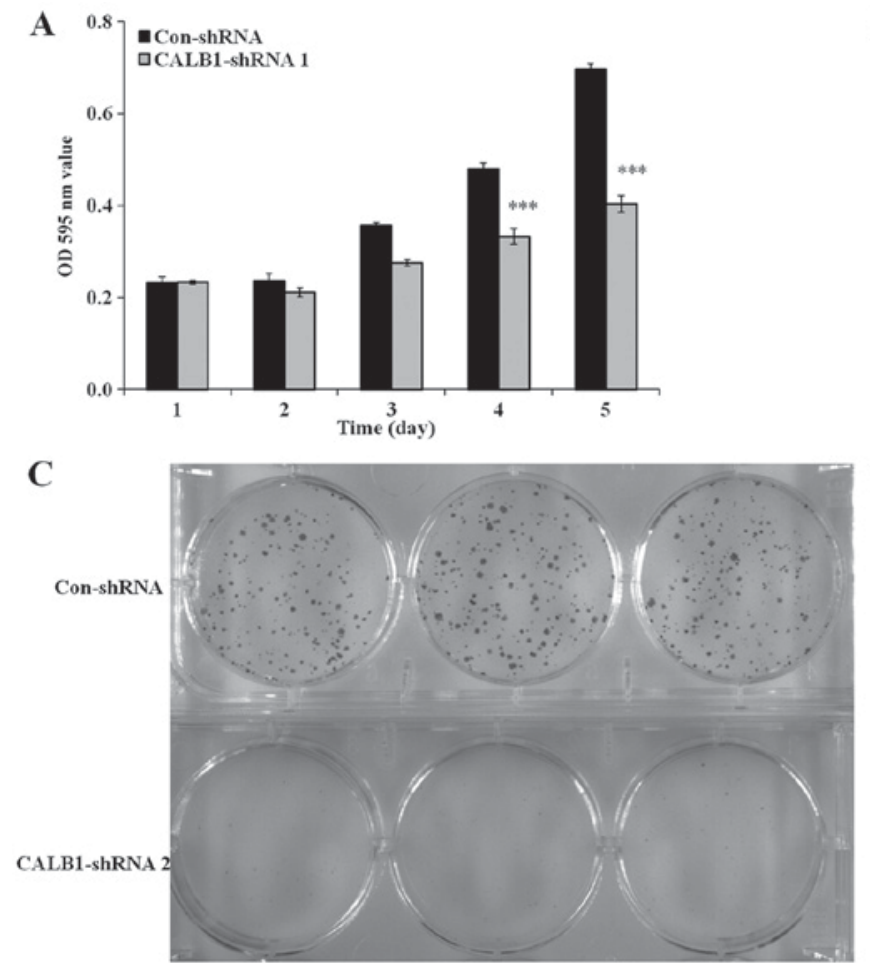

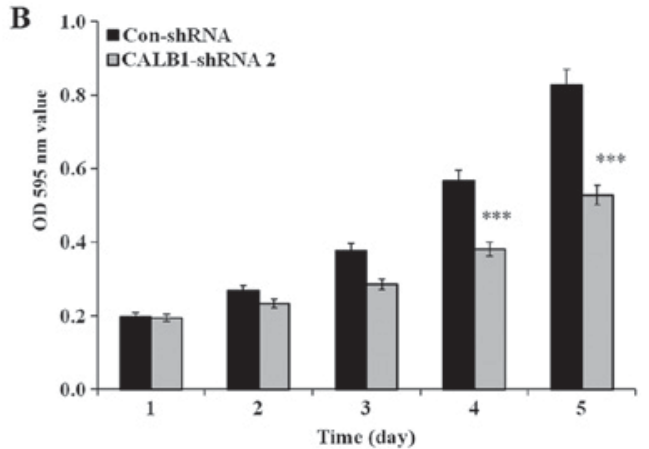

D

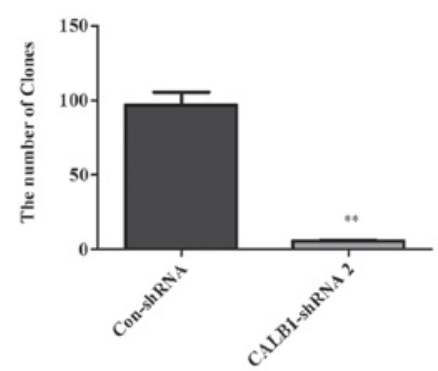

Figure 2. CALB1-knockdown significantly inhibits proliferation and colony formation in osteosarcoma U2OS cells. The cell proliferation activity was decreased in the (A) CALB1-shRNA 1 and (B) CALB1-shRNA 2 groups, as measured by MTT assay, compared with the control group. (C) The reduced colony-forming ability of the CALB1-shRNA 2 cells compared with the control group was observed following a crystal violet staining assay subsequent to 9 days culture. Scale bar, $25 \mu \mathrm{m}$. (D) The colony number of U2OS cells was significantly reduced following treatment with CALB1-shRNA 2 compared with that in the Con-shRNA-infected group. ${ }^{* *} \mathrm{P}<0.01,{ }^{* * *} \mathrm{P}<0.001$. CALB1, calbindin 1; sh, short hairpin; con, negative control; OD, optical density.

A

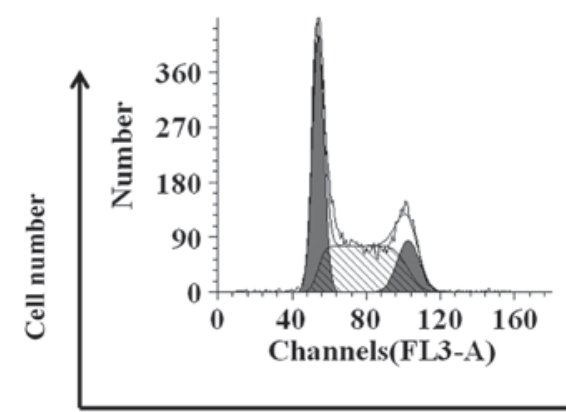

DNA content

B

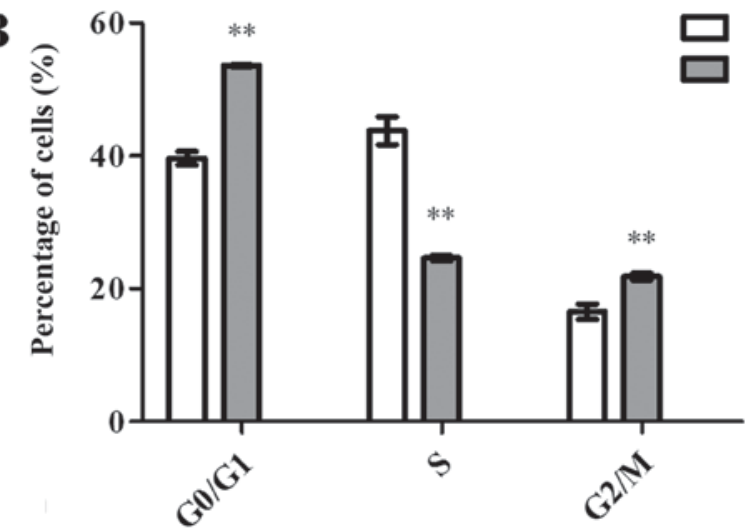

CALB1-shRNA 2

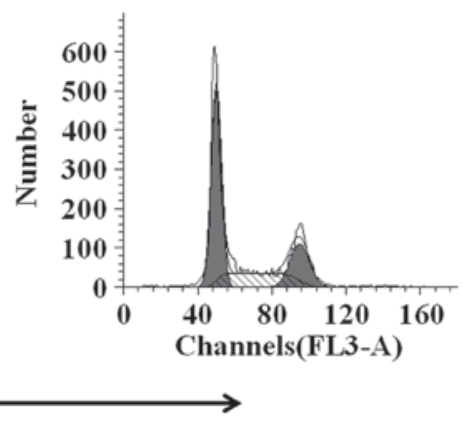

\section{Con-shRNA}

CALB1-shRNA 2

Figure 3. Knockdown of $C A L B 1$ with CALB1-shRNA 2 induces cell cycle arrest at $\mathrm{G}_{0} / \mathrm{G}_{1}$ and $\mathrm{G}_{2} / \mathrm{M}$ phase in $\mathrm{U} 2 \mathrm{OS}$ cells. (A) The cell cycle distribution of the U2OS cells was determined using flow cytometry following infection with CALB1-shRNA 2 and Con-shRNA. (B) An accumulation of $\mathrm{U}_{2} \mathrm{OS}$ cells in $\mathrm{G}_{0} / \mathrm{G}_{1}$ and $\mathrm{G}_{2} / \mathrm{M}$ phases occurred due to the downregulation of $C A L B 1$. The first grey peak is the diploid peak $(\mathrm{G} 0 / \mathrm{G} 1)$, the second peak in grey is the tetraploid peak (G2/M). The middle part in white and striped colors/patterns, represents cells that at $\mathrm{S}$ phase (DNA content between $2 \mathrm{~N}$ to $4 \mathrm{~N}$ ). ${ }^{* *} \mathrm{P}<0.01$. CALB1, calbindin 1; sh, short hairpin; con, negative control. 
A

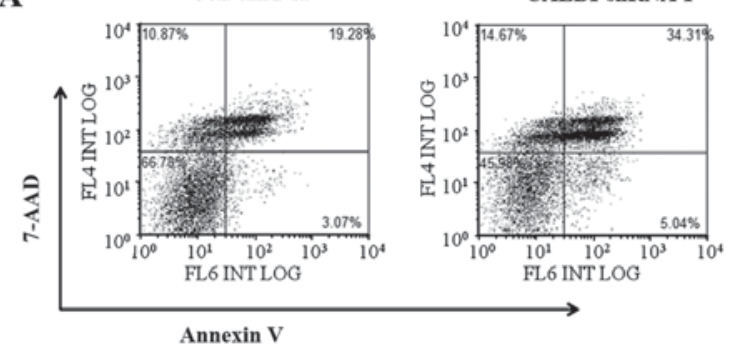

CALB1-shRNA 2

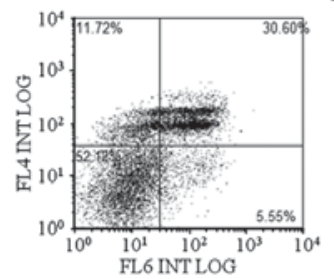

B ๑ $^{80} 1$ 口 Con-shRNA

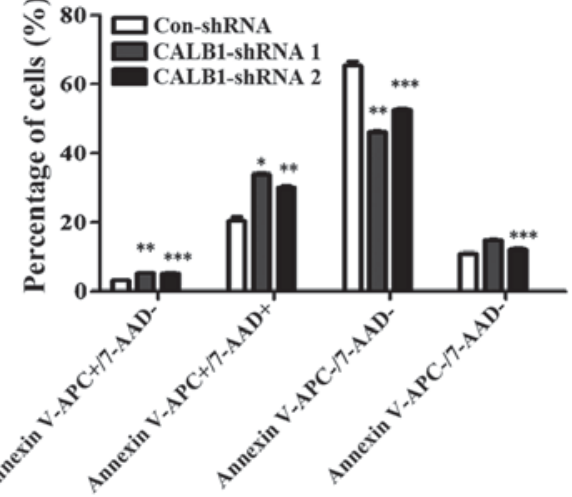

Figure 4. CALB1 depletion causes necrosis and apoptosis of osteosarcoma U2OS cells. (A) The apoptotic death of U2OS cells administered with three treatments, Con-shRNA, CALB1-shRNA 1 and CALB1-shRNA 2, was determined through Annexin V-APC/7-AAD double staining and analyzed using flow cytometry. (B) Deficiency of CALB1 in U2OS cells could trigger necrosis, and early and late apoptosis. $\mathrm{AP}^{\mathrm{C}-} / 7-\mathrm{AAD}^{-}$and $\mathrm{APC}^{-/ 7}-\mathrm{AAD}^{+}$along the horizontal axis represent viable and necrotic cells, while $\mathrm{APC}^{+} / 7-\mathrm{AAD}^{-}$and $\mathrm{APC}^{+} / 7-\mathrm{AAD}^{+}$represent early and late apoptotic cells respectively. ${ }^{*}<0.05{ }^{* * *} \mathrm{P}<0.01$, and ${ }^{* * * *} \mathrm{P}<0.001$ vs. Con-shRNA. CALB1, calbindin 1; sh, short hairpin; con, negative control.

and $\mathrm{G}_{0} / \mathrm{G}_{1}$ phases. This was also demonstrated to occur in bladder cancer cells following the knockdown of survivin, which resulted in $\mathrm{G}_{2} / \mathrm{M}$ arrest and the induction of apoptosis (33). In addition, a previous study demonstrated that decreased expression of ALG2 $\alpha$-1,3/1,6-mannosyltransferase in HeLa cells induced $\mathrm{G}_{2} / \mathrm{M}$ cell cycle phase accumulation, and early and late apoptosis (34). The results of the present study indicate that $C A L B 1$-knockdown may regulate mitosis genes to inhibit mitotic progression at the latter stage.

It has been typically demonstrated that apoptosis is an important component in cancer pathogenesis (35). The inhibition of apoptosis facilitates the growth of tumors (34). CALB1 is a calcium-binding protein and is responsible for maintaining low levels of intracellular calcium (36). Calbindin, by buffering calcium, functions to inhibit nerve cell apoptosis when induced by high levels of intracellular calcium (21). The present study revealed that the number of early apoptotic, late apoptotic and necrotic cells were significantly reduced in $C A L B 1$-knockdown U2OS cells. These results suggest that the knockdown of $C A L B 1$ may increase the concentrations of intracellular calcium, resulting in a promotion of apoptosis in U2OS cells, and contributing to the decrease in cell proliferation and colony formation.

$C A L B 1$ inhibits the activity of caspase-3, a downstream effector of multiple apoptotic signaling pathways, and that inhibition results in an inhibition of apoptosis in osteoblastic cells (21,37). CALB1 may also protect against apoptosis in dopaminergic neurons through activation of the phosphoinositide 3 (PI3) kinase-Akt signaling pathway (38). In the present study, the knockdown of CALB1 may have accelerated U2OS apoptosis via the activation of caspase- 3 and/or by the inactivation of the PI3-kinase-Akt signaling pathway, which is dependent on the calcium binding activity of CALB1.

In conclusion, the present study demonstrated that $C A L B 1-$ knockdown inhibits the proliferation and colony formation of osteosarcoma U2OS cells. The suppression of $C A L B 1$ inhibited human osteosarcoma cell growth through modulation of the cell cycle and the induction of apoptosis, and may be a potential therapeutic target for the treatment of patients with osteosarcoma.

\section{References}

1. Maire G, Martin JW, Yoshimoto M, Chilton-MacNeill S, Zielenska $M$ and Squire JA: Analysis of miRNA-gene expression-genomic profiles reveals complex mechanisms of microRNA deregulation in osteosarcoma. Cancer Genet 204: 138-146, 2011.

2. Ottaviani G and Jaffe N: The epidemiology of osteosarcoma. In: Pediatric and Adolescent Osteosarcoma. Jaffe N, Bruland OS and Bielack S (eds). Springer, New York, pp3-13, 2010.

3. Kobayashi E, Hornicek FJ and Duan Z: MicroRNA involvement in osteosarcoma. Sarcoma 2012: 359739, 2012.

4. Leithner A, Maurer-Ertl W, Glehr M, Friesenbichler J, Leithner K and Windhager R: Wikipedia and osteosarcoma: A trustworthy patients' information? J Am Med Inform Assoc 17: 373-374, 2010.

5. Ternovoi VV, Curiel DT, Smith BF and Siegal GP: Adenovirus-mediated p53 tumor suppressor gene therapy of osteosarcoma. Lab Invest 86: 748-766, 2006.

6. Ma Y, Ren Y, Han EQ, Li H, Chen D, Jacobs JJ, Gitelis S, O'Keefe RJ, Konttinen YT, Yin G and Li TF: Inhibition of the Wnt- $\beta$-catenin and Notch signaling pathways sensitizes osteosarcoma cells to chemotherapy. Biochem Biophys Res Commun 431: 274-279, 2013.

7. Ando K, Mori K, Corradini N, Redini F and Heymann D: Mifamurtide for the treatment of nonmetastatic osteosarcoma. Expert Opin Pharmacother 12: 285-292, 2011.

8. Ferguson WS, Harris MB, Goorin AM, Gebhardt MC, Link MP, Shochat SJ, Siegal GP, Devidas M and Grier HE: Presurgical window of carboplatin and surgery and multidrug chemotherapy for the treatment of newly diagnosed metastatic or unresectable osteosarcoma: Pediatric Oncology Group Trial. J Pediatr Hematol Oncol 23: 340-348, 2001

9. Jaffe N: Osteosarcoma: Review of the Past, Impact on the Future. The American Experience. In: Pediatric and Adolescent Osteosarcoma. Jaffe N, Bruland OS and Bielack S (eds). Springer, NY, pp239-262, 2010.

10. Jones KB, Salah Z, Del Mare S, Galasso M, Gaudio E, Nuovo GJ, Lovat F, LeBlanc K, Palatini J, Randall RL, et al: miRNA signatures associate with pathogenesis and progression of osteosarcoma. Cancer Res 72: 1865-1877, 2012.

11. Cross D and Burmester JK: Gene therapy for cancer treatment: Past, present and future. Clin Med Res 4: 218-227, 2006.

12. Zhang YW, Morita I, Ikeda M, Ma KW and Murota S: Connexin43 suppresses proliferation of osteosarcoma U2OS cells through post-transcriptional regulation of p27. Oncogene 20: 4138-4149, 2001.

13. Ma X, Yang Y, Wang Y, An G and Lv G: Small interfering RNA-directed knockdown of S100A4 decreases proliferation and invasiveness of osteosarcoma cells. Cancer Lett 299: 171-181, 2010

14. Zhang K, Tian F, Zhang Y, Zhu Q, Xue N, Zhu H, Wang H and Guo X: MACC1 is involved in the regulation of proliferation, colony formation, invasion ability, cell cycle distribution, apoptosis and tumorigenicity by altering Akt signaling pathway in human osteosarcoma. Tumor Biol 35: 2537-2548, 2014. 
15. Reiche D, Pfannkuche H, Michel K, Hoppe S and Schemann M Immunohistochemical evidence for the presence of calbindin containing neurones in the myenteric plexus of the guinea-pig stomach. Neurosci Lett 270: 71-74, 1999.

16. Parmentier M, Passage E, Vassart G and Mattei MG: The human calbindin D28k (CALB1) and calretinin (CALB2) genes are located at 8q21.3----q22.1 and 16q22----q23, respectively, suggesting a common duplication with the carbonic anhydrase isozyme loci. Cytogenet Cell Genet 57: 41-43, 1991.

17. Lee CT, Huynh VM, Lai LW and Lien YH: Cyclosporine A-induced hypercalciuria in calbindin-D28k knockout and wild-type mice. Kidney Int 62: 2055-2061, 2002.

18. Margolis DS, Kim D, Szivek JA, Lai LW and Lien YH: Functionally improved bone in calbindin-D28k knockout mice. Bone 39: 477-484, 2006.

19. Rabinovitch A, Suarez-Pinzon WL, Sooy K, Strynadka K and Christakos S: Expression of calbindin-D28k in a pancreatic Islet $\beta$-Cell line protects against cytokine-induced apoptosis and necrosis. Endocrinology 142: 3649-3655, 2001.

20. Liu Y, Porta A, Peng X, Gengaro K, Cunningham EB, Li H Dominguez LA, Bellido T and Christakos S: Prevention of Glucocorticoid-Induced Apoptosis in Osteocytes and Osteoblasts by Calbindin-D28k. J Bone Miner Res 19: 479-490, 2004

21. Bellido T, Huening M, Raval-Pandya M, Manolagas SC and Christakos S: Calbindin-D28k is expressed in osteoblastic cells and suppresses their apoptosis by inhibiting caspase-3 activity. J Biol Chem 275: 26328-26332, 2000.

22. Sottnik JL, Campbell B, Mehra R, Behbahani-Nejad O, Hall CL and Keller ET: Osteocytes serve as a progenitor cell of osteosarcoma. J Cell Biochem 115: 1420-1429, 2014.

23. Livak KJ and Schmittgen TD: Analysis of relative gene expression data using real-time quantitative PCR and the 2(-Delta Delta C(T)) method. Methods 25: 402-408, 2001.

24. Marina N, Gebhardt M, Teot L and Gorlick R: Biology and therapeutic advances for pediatric osteosarcoma. Oncologist 9 : 422-441, 2004

25. Trieb K, Lehner R, Stulnig T, Sulzbacher I and Shroyer KR: Survivin expression in human osteosarcoma is a marker for survival. Eur J Surg Oncol 29: 379-382, 2003.

26. Katsetos CD, Herman MM, Krishna L, Vender JR, Vinores SA, Agamanolis DP, Schiffer D, Burger PC and Urich $\mathrm{H}$ : Calbindin-D28k in subsets of medulloblastomas and in the human medulloblastoma cell line D283 Med. Arch Pathol Lab Med 119: 734-743, 1995.
27. Castro CY, Stephenson M, Gondo MM, Medeiros LJ and Cagle PT: Prognostic implications of calbindin-D28k expression in lung cancer: Analysis of 452 cases. Mod Pathol 13: 808-813, 2000.

28. Hanahan D and Weinberg RA: The hallmarks of cancer. Cell 100: 57-70, 2000.

29. Hanahan D and Weinberg RA: Hallmarks of cancer: The next generation. Cell 144: 646-674, 2011

30. Fang K, Fu W, Beardsley AR, Sun X, Lisanti MP and Liu J: Overexpression of caveolin-1 inhibits endothelial cell proliferation by arresting the cell cycle at G0/G1 phase. Cell Cycle 6: 199-204, 2007.

31. Wang T, Hao L, Feng Y, Wang G, Qin D and Gu G: Knockdown of MED19 by lentivirus-mediated shRNA in human osteosarcoma cells inhibits cell proliferation by inducing cell cycle arrest in the G0/G1 phase. Oncol Res 19: 193-201, 2011.

32. Wang JS, Ji AF, Wan HJ, Lu YL, Yang JZ, Ma LL, Wang YJ and Wei W: Gene Silencing of B-catenin by RNAi inhibits proliferation of human esophageal cancer cells by inducing G0/G1 cell cycle arrest. Asian Pac J Cancer Prev 13: 2527-2532, 2012.

33. Ning S, Fuessel S, Kotzsch M, Kraemer K, Kappler M, Schmidt U, Taubert H, Wirth MP and Meye A: siRNA-mediated down-regulation of survivin inhibits bladder cancer cell growth. Int J Oncol 25: 1065-1071, 2004.

34. Høj BR, la Cour JM, Mollerup J and Berchtold MW: ALG-2 knockdown in HeLa cells results in G2/M cell cycle phase accumulation and cell death. Biochem Biophys Res Commun 378: 145-148, 2009.

35. Hunter AM, LaCasse EC and Korneluk RG: The inhibitors of apoptosis (IAPs) as cancer targets. Apoptosis 12: 1543-1568, 2007.

36. Rintoul GL, Raymond LA and Baimbridge KG: Calcium buffering and protection from excitotoxic cell death by exogenous calbindin-D28k in HEK 293 cells. Cell calcium 29: 277-287, 2001.

37. Christakos S and Liu Y: Biological actions and mechanism of action of calbindin in the process of apoptosis. J Steroid Biochem Mol Biol 89-90: 401-404, 2004.

38. Sun S, Li F, Gao X, Zhu Y, Chen J, Zhu X, Yuan H and Gao D: Calbindin-D28K inhibits apoptosis in dopaminergic neurons by activation of the PI3-kinase-Akt signaling pathway. Neuroscience 199: 359-367, 2011. 